Check for updates

Cite this: Chem. Sci., 2019, 10, 2373

๑ All publication charges for this article have been paid for by the Royal Society of Chemistry

Received 13th November 2018 Accepted 27th December 2018 DOI: $10.1039 / c 8 s c 05056 b$ rsc.li/chemical-science

\section{Consequences of exchange-site heterogeneity and dynamics on the UV-visible spectrum of Cu-exchanged SSZ-13†}

\author{
Hui Li, (D) $\ddagger^{\mathrm{a}}$ Christopher Paolucci, (D) $\ddagger^{\text {ab }}$ Ishant Khurana, (D) ${ }^{\mathrm{c}}$ Laura N. Wilcox, ${ }^{\mathrm{c}}$ \\ Florian Göltl, iD d Jonatan D. Albarracin-Caballero, ${ }^{\mathrm{C}}$ Arthur J. Shih, ID c \\ Fabio H. Ribeiro, (D) Rajamani Gounder (D) *c and William F. Schneider (D) *a
}

\begin{abstract}
The speciation and structure of Cu ions and complexes in chabazite (SSZ-13) zeolites, which are relevant catalysts for nitrogen oxide reduction and partial methane oxidation, depend on material composition and reaction environment. Ultraviolet-visible (UV-Vis) spectra of Cu-SSZ-13 zeolites synthesized to contain specific $\mathrm{Cu}$ site motifs, together with ab initio molecular dynamics and time-dependent density functional theory calculations, were used to test the ability to relate specific spectroscopic signatures to specific site motifs. Geometrically distinct arrangements of two framework Al atoms in six-membered rings are found to exchange $\mathrm{Cu}^{2+}$ ions that become spectroscopically indistinguishable after accounting for the finite-temperature fluctuations of the $\mathrm{Cu}$ coordination environment. Nominally homogeneous single Al exchange sites are found to exchange a heterogeneous mixture of $[\mathrm{CuOH}]^{+}$monomers, $\mathrm{O}$ - and $\mathrm{OH}$-bridged $\mathrm{Cu}$ dimers, and larger polynuclear complexes. The UV-Vis spectra of the latter are sensitive to framework Al proximity, to precise ligand environment, and to finite-temperature structural fluctuations, precluding the precise assignment of spectroscopic features to specific Cu structures. In all Cu-SSZ-13 samples, these dimers and larger complexes are reduced by $\mathrm{CO}$ to $\mathrm{Cu}^{+}$sites at $523 \mathrm{~K}$, leaving behind isolated $[\mathrm{CuOH}]^{+}$sites with a characteristic spectroscopic identity. The various mononuclear and polynuclear $\mathrm{Cu}^{2+}$ species are distinguishable by their different responses to reducing environments, with implications for their relevance to catalytic redox reactions.
\end{abstract}

\section{Introduction}

Copper ions exchanged onto zeolites are implicated as active sites for the selective catalytic reduction of nitrogen oxides, ${ }^{\mathbf{1 1 0}}$ oxidation of $\mathrm{NO}$ to $\mathrm{NO}_{2},{ }^{11,12}$ decomposition of $\mathrm{NO}$ and $\mathrm{N}_{2} \mathrm{O},{ }^{13-16}$ and partial methane oxidation to methanol. ${ }^{17-33}$ These $\mathrm{Cu}$ ions are associated with charge-compensating $\mathrm{AlO}_{4}{ }^{-}$tetrahedral sites that are distributed throughout the zeolite lattice. Because these Al substitutions are not ordered under typical zeolite synthesis conditions, a given framework and macroscopic Si/Al ratio will present a heterogeneous distribution of microscopic $\mathrm{Al}$ site ensembles, each of which provides a distinct exchange

\footnotetext{
${ }^{a}$ Department of Chemical and Biomolecular Engineering, University of Notre Dame, 182 Fitzpatrick Hall, Notre Dame, IN 46556, USA. E-mail: wschneider@nd.edu

${ }^{b}$ Department of Chemical Engineering, University of Virginia, 102 Engineer's Way, Charlottesville, VA 22904, USA

${ }^{\prime}$ Charles D. Davidson School of Chemical Engineering, Purdue University, 480 Stadium Mall Drive, West Lafayette, IN 47907, USA. E-mail: rgounder@purdue.edu

${ }^{d}$ Department of Chemical and Biological Engineering, University of WisconsinMadison, 1415 Engineering Drive, Madison, WI 53706, USA

$\dagger$ Electronic supplementary information (ESI) available. See DOI: $10.1039 / \mathrm{c} 8 \mathrm{sc} 05056 \mathrm{~b}$

† Contributed equally to this work.
}

environment for a $\mathrm{Cu}$ ion. The precise $\mathrm{Cu}$ species and their relative densities in a given material are thus functions of framework topology, ${ }^{34-37}$ of the density and underlying distribution of framework $\mathrm{Al}(\mathrm{Si} / \mathrm{Al})$, of the $\mathrm{Cu}$ loading $(\mathrm{Cu} / \mathrm{Al})$, and even of the protocols used to introduce $\mathrm{Cu}$ onto the zeolite supports. ${ }^{38-44}$ Further, multiple $\mathrm{Cu}$ ion site motifs may be of similar free energy at a given $\mathrm{Al}$ site or ensemble, and at finite temperatures these motifs may interchange at timescales relevant to observation or to catalytic turnover. ${ }^{45-47}$ Given these many sources of structural diversity, assignment of spectroscopic features to specific $\mathrm{Cu}$ motifs in a heterogeneous solid is a non-trivial endeavor, but a critical one to make connections between local structure and catalytic function.

One strategy to reduce this complexity is to intentionally synthesize zeolites with framework $\mathrm{Al}$ distributions that present one or a few distinct $\mathrm{Al}$ site ensembles. This strategy is particularly promising for zeolites of relatively high symmetry, such as the chabazite (SSZ-13) framework that is composed of a single symmetry-distinct tetrahedral site. SSZ-13 samples synthesized using only organic $\mathrm{N}, \mathrm{N}, \mathrm{N}$-trimethyl-1-adamantylammonium (TMAda $^{+}$) structure-directing cations nominally contain only isolated framework $\mathrm{Al}$ sites, ${ }^{39}$ and are found to contain predominantly $[\mathrm{CuOH}]^{+}$ions after aqueous $\mathrm{Cu}$ ion exchange and high 
temperature $(>473 \mathrm{~K})$ oxidation, based on titrimetric analysis and vibrational and X-ray spectroscopies. ${ }^{38}$ In contrast, SSZ-13 samples synthesized in the presence of TMAda $^{+}$and $\mathrm{Na}^{+}$as costructure-directing cations ${ }^{39}$ contain detectable fractions of paired $\mathrm{Al}$ sites in 6-membered rings (6MR). After $\mathrm{Cu}$ ion exchange and high temperature oxidative treatment, these paired $\mathrm{Al}$ sites are observed to preferentially host $\mathrm{Cu}^{2+}$ ions $\left(\mathrm{Z}_{2} \mathrm{Cu}\right)$ before isolated $\mathrm{Al}$ sites are occupied by $[\mathrm{CuOH}]^{+}$ions $(\mathrm{ZCuOH}) \cdot{ }^{38} \mathrm{Z}_{2} \mathrm{Cu}$ and $\mathrm{ZCuOH}$ are expected to contribute differently to ultraviolet-visible (UV-Vis) absorption spectra based on ligand-field arguments and density functional theory (DFT) calculations, consistent with dd transition and ligand-to-metal charge transfer (LMCT) features in experimentally-measured UV-Vis spectra that are observed to change with $\mathrm{Cu}$ content in Cu-SSZ-13 samples. ${ }^{\mathbf{6} 48-50}$

These single $\mathrm{Cu}$ species may coexist with dimeric or higher nuclearity $\mathrm{Cu}$ clusters. Oxygen-bridged $\mathrm{Cu}$ dimers are well established to be present and quantifiable with CO temperature programmed reduction, ${ }^{15}$ to be plausible active sites for $\mathrm{NO}$ and $\mathrm{N}_{2} \mathrm{O}$ decomposition ${ }^{\mathbf{1 4 , 1 5 , 5 1 - 5 3}}$ and partial $\mathrm{CH}_{4}$ oxidation in $\mathrm{Cu}$-exchanged zeolites, ${ }^{17,30,33,54-62}$ including Raman $^{63,64}$ and UV-Vis $^{\mathbf{1 4 , 5 5}}$ spectroscopic observations and CO temperature programmed reduction to quantify such sites. In Cu-SSZ-13 samples of certain composition $(\mathrm{Si} / \mathrm{Al}=5, \mathrm{Cu} / \mathrm{Al}=0.3-1.6)$, oxygen-bridged $\mathrm{Cu}$ dimers and larger $\mathrm{Cu}$ oxide aggregates are detected by X-ray spectroscopy and are the dominant active sites for $\mathrm{NO}$ oxidation to $\mathrm{NO}_{2}$ under dry conditions. ${ }^{11} \mathrm{UV}-\mathrm{Vis}$ spectra of certain Cu-SSZ-13 samples $(\mathrm{Si} / \mathrm{Al}=13, \mathrm{Cu} / \mathrm{Al}=$ 0.45) following high temperature $\mathrm{O}_{2}$ treatment show features consistent with those for oxygen-bridged $\mathrm{Cu}$ dimers, ${ }^{48}$ and these features disappear upon reduction with $\mathrm{CH}_{4},{ }^{\mathbf{1 8 , 5 0}}$ implicating them as active sites for partial methane oxidation. The precise relationship between sample composition and treatment history, and the numbers and structures of $\mathrm{Cu}$ dimers or larger aggregates formed, however, remains less well resolved than such relationships for monomeric $\mathrm{Cu}$ sites in $\mathrm{Cu}-\mathrm{SSZ}-13$.

Here, we report UV-Vis spectra of model Cu-SSZ-13 zeolites prepared to contain predominantly $\mathrm{Z}_{2} \mathrm{Cu}$ or $\mathrm{ZuOH}$ sites, by virtue of their different framework $\mathrm{Al}$ arrangements and elemental compositions. We use supercell time-dependent DFT (TD-DFT) calculations to correlate observed UV-Vis spectral features with specific $\mathrm{Cu}$ motifs. We find that spectra computed for single, static, minimum energy structures are in poor agreement with experimental observation, because $\mathrm{Cu}$ ion dynamics have a significant impact on computed spectral features even at ambient temperature. We construct synthetic spectra by averaging over configurations visited during finitetemperature $a b$ initio molecular dynamics (AIMD) simulations and show that these dynamically averaged spectra correspond closely with experimental observation. Further, experimental and simulated spectra are compared to identify features associated with a confounding subset of $\mathrm{Cu}$ dimers or larger aggregates in samples prepared to contain predominantly $[\mathrm{CuOH}]^{+}$species. These results resolve several inconsistencies in spectral and site assignments reported in Cu-exchanged zeolites.

\section{Results}

\section{$2.1 \mathrm{Z}_{2} \mathrm{Cu}$}

First, UV-Vis spectra were collected on a Cu-SSZ-13 sample that contains only $\mathrm{Z}_{2} \mathrm{Cu}$ sites. ${ }^{\mathbf{3 8 , 6 5}}$ This sample was prepared by starting from an SSZ-13 sample ( $\mathrm{Si} / \mathrm{Al}=5)$ crystallized using a mixture of TMAda $^{+}$and $\mathrm{Na}^{+}$cations to contain a finite and detectable fraction of paired $\mathrm{Al}$ sites, ${ }^{39}$ followed by aqueous ion exchange with a cupric nitrate solution to achieve a composition $(\mathrm{Cu} / \mathrm{Al}=0.21)$ demonstrated previously to contain only isolated $\mathrm{Z}_{2} \mathrm{Cu}$ sites through $\mathrm{X}$-ray absorption spectroscopy, Brønsted acid site exchange stoichiometries with $\mathrm{Cu}^{2+}$ and $\mathrm{Co}^{2+}$ $\left(2 \mathrm{H}^{+}\right.$replaced per $\mathrm{Cu}^{2+}$ or $\left.\mathrm{Co}^{2+}\right)$, and IR spectroscopy ${ }^{38}$ (sample preparation details in ESI Section S2.1 and elemental analysis in ESI Table $\mathrm{S} 4 \dagger$ ). This Cu-SSZ-13 sample was treated in flowing dry air to $673 \mathrm{~K}$ for $2 \mathrm{~h}$, cooled to $300 \mathrm{~K}$, and UV-Vis spectra were collected from 7000 to $50000 \mathrm{~cm}^{-1}$. Spectra are reported in quasi-absorption (K-M) units in Fig. 1a, and show a broad dd transition feature from about 8000 to $16000 \mathrm{~cm}^{-1}$ characteristic of $\mathrm{a} \mathrm{d}^{9} \mathrm{Cu}^{2+}$ ion and a broad ligand-to-metal charge transfer (LMCT) feature from about 30000 to $50000 \mathrm{~cm}^{-1}$. The spectrum is consistent with that previously reported for a $\mathrm{Cu}-$ SSZ-13 sample after high temperature oxidative treatment. ${ }^{6}$

The $\mathrm{Cu}^{2+}$ ions in this zeolite sample are associated with ensembles of two $\mathrm{Al}$ centers separated by two or one intervening Si tetrahedral (T-) sites in the same six-membered ring (6MR), which we term "para" and "meta" respectively. We used a triclinic 12 T-site SSZ-13 supercell described elsewhere ${ }^{11,66}$ to represent each ensemble (Fig. 2). In each case, a single $\mathrm{Cu}$ ion was placed within the $6 \mathrm{MR}$ and the structure annealed at $673 \mathrm{~K}$ for 150 ps using thermostated AIMD (computational details in ESI Section S1†). 400 equally spaced configurations were extracted from the trajectories and relaxed. In each Al ensemble, all configurations relaxed to one of three energy minima shown in Fig. 2a and e. These three minima differ in the combination of Al-adjacent and non-Al-adjacent framework oxygen $\left(\mathrm{O}_{\mathrm{f}}\right)$ that comprise the first $\mathrm{Cu}$ coordination sphere. The framework distorts to accommodate these different Cu-containing minima, behavior consistent with structural distortions reported previously in calculations of metal-exchanged MFI, ${ }^{67,68} \mathrm{MOR},{ }^{67,69}$ and $\mathrm{FER}^{70}$ and inferred from the appearance of two T-O-T deformation bands $\left(900,950 \mathrm{~cm}^{-1}\right.$ ) in DRIFTS spectra after $\mathrm{Cu}$ exchange into SSZ-13. ${ }^{71}$ Despite these structural differences, the three para configurations differ in energy by less than 5 and meta by less than $20 \mathrm{~kJ} \mathrm{~mol}^{-1}$ (Fig. 2a, e, and also ESI Table S1 $\dagger$ ). The lowest-energy para and meta configurations differ in absolute energy by $21 \mathrm{~kJ} \mathrm{~mol}^{-1}$ (ESI Table S1†).

We performed additional AIMD at $300 \mathrm{~K}$ to gain insight into variations in $\mathrm{Cu}$ coordination environment at finite temperature $^{38,72}$ that might influence the observed spectra. Fig. $2 b$ reports histograms of distances between $\mathrm{Cu}$ and each of the six $6 \mathrm{MR} \mathrm{O}_{\mathrm{f}}$, collected at $0.6 \mathrm{fs}$ intervals over the $150 \mathrm{ps}$ simulation of para $\mathrm{Z}_{2} \mathrm{Cu}$. Distances segregate into two groups centered at 2.1 and $3.3 \AA$, corresponding to $\mathrm{Cu}$-coordinated and free $\mathrm{O}_{\mathrm{f}}$, each group having widths $>0.5 \AA$ (Table $\mathrm{S} 2 \dagger$ ) that arise from finite temperature fluctuations of the lattice and $\mathrm{Cu}$. The 

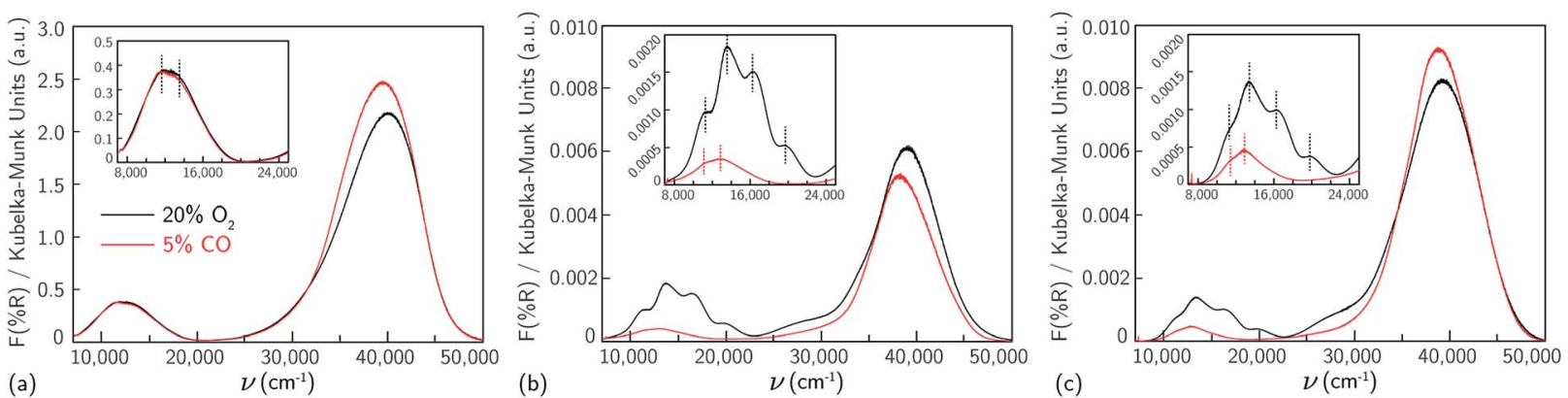

Fig. 1 UV-visible spectra collected at $300 \mathrm{~K}$ of samples containing predominantly (a) $\mathrm{Z}_{2} \mathrm{Cu}(\mathrm{Si} / \mathrm{Al}=5, \mathrm{Cu} / \mathrm{Al}=0.21),(\mathrm{b}) \mathrm{ZCuOH}(\mathrm{Si} / \mathrm{Al}=15, \mathrm{Cu} / \mathrm{Al}$ $=0.24)$ and $(\mathrm{c}) \mathrm{ZCuOH}(\mathrm{Si} / \mathrm{Al}=15, \mathrm{Cu} / \mathrm{Al}=0.15)$, after $20 \% \mathrm{O}_{2}$ treatment at $673 \mathrm{~K}$ (black), and $5 \% \mathrm{CO}$ treatment at $523 \mathrm{~K}$ (red). Insets show magnification of the $d-d$ transition region.

unimodal $\mathrm{O} 1, \mathrm{O} 2$, and $\mathrm{O} 3$ and bimodal $\mathrm{O} 4, \mathrm{O} 5$, and $\mathrm{O} 6$ distributions are due to transitions between the three different minimum energy configurations of Fig. 2a. Inspection of the trajectory shows that transitions occur by extension of the four $\mathrm{Cu}-\mathrm{O}_{\mathrm{f}}$ bonds, distortion of the lattice, and relaxation into an adjacent minimum. We used these observations to categorize each AIMD frame into one of the three minima or into an intermediate state (example structure in ESI Fig. S2 $\uparrow$ ), based on the identity and number of $\mathrm{O}_{\mathrm{f}}$ within $2.6 \AA$ of $\mathrm{Cu}$, chosen to represent the upper bound of a $\mathrm{Cu}-\mathrm{O}$ coordination and shown in the pie chart inset to Fig. 2b. All three minima are visited, and the fractions of time spent in each is generally consistent with the relative energies of the corresponding minima. A nonnegligible fraction of time is also spent outside any minimum.

Analogous results for meta $\mathrm{Z}_{2} \mathrm{Cu}$ are shown in Fig. 2f. Again, $\mathrm{Cu}-\mathrm{O}_{\mathrm{f}}$ distances segregate into the same two groups, and the aggregate histogram of all $\mathrm{Cu}-\mathrm{O}_{\mathrm{f}}$ distances have identical means and standard deviations in the para and meta cases. The individual $\mathrm{Cu}-\mathrm{O}_{\mathrm{f}}$ histograms are all unimodal. The large energy difference between minima guarantees that meta $\mathrm{Z}_{2} \mathrm{Cu}$ remains in the lowest energy configuration throughout the simulation.

We used TD-DFT to compute frequency-dependent dielectric tensors and corresponding optical absorption spectra of the six minima. The computational details and codes for the VASP inputs and subsequent analysis are provided in ESI Section S1.2 $\uparrow$ and also on the external Zenodo repository (DOI: 10.5281/ zenodo.1473128). Computed spectra are shown in Fig. 2c and g, reported in arbitrary $\mathrm{K}-\mathrm{M}$ units. All six spectra exhibit features in the $\mathrm{d}-\mathrm{d}$ and LMCT regions not evident in the experimental spectrum in Fig. 1a. Coordinatively similar (as measured from $\mathrm{Cu}-\mathrm{O}$ distances and $\mathrm{O}-\mathrm{Cu}-\mathrm{O}$ angles) para minima 1 and 3 and meta minimum 2 exhibit equivalent spectra. Absolute intensities are greatest for lowest symmetry and least for highest symmetry minima. ${ }^{73}$ Neither any individual spectrum nor a Boltzmann weighting of all spectra at $300 \mathrm{~K}$ (shown in ESI Fig. S3†) recovers the experimental spectrum in Fig. 1a.

To simulate the effects of these geometric variations on observed spectra, we computed the absorption spectra of 400 equally spaced snapshots from the $300 \mathrm{~K}$ AIMD trajectories (ESI Fig. S4a (para) and $b$ (meta) $\dagger$ ). Individual spectra are sensitive to local structure. The $\mathrm{d}-\mathrm{d}$ transitions shift generally to higher frequency with decreasing mean $\mathrm{Cu}-\mathrm{O}_{\mathrm{f}}$ distance (ESI Fig. $\mathrm{S} 5 \dagger$ ), consistent with behavior expected from ligand field arguments. The LMCT features do not simply correlate with the $\mathrm{Cu}-\mathrm{O}_{\mathrm{f}}$ distances. Fig. $2 \mathrm{~d}$ and $\mathrm{h}$ show the results of averaging increasing numbers of spectra computed from configurations extracted with equal spacing along the AIMD trajectories. Sharp features in both the d-d and LMCT regions become broadened upon averaging an increasing number of spectra from 1 to 200 structures and converge at approximately 200 structures, as evidenced by the small changes resulting from further averaging up to 400 structures. In contrast to spectra computed from the minimum energy structures, the final averaged meta and para UV-Vis spectra are indistinguishable and consistent with experimental observations in Fig. 1a.

\section{$2.2 \quad \mathrm{ZCuOH}$}

For comparison to the sample containing predominantly $\mathrm{Z}_{2} \mathrm{Cu}$ sites, we synthesized different Cu-SSZ-13 samples that contain predominantly the $\mathrm{ZCuOH}$ site motif that results when $\mathrm{Cu}^{2+}$ ions are exchanged near isolated framework Al sites. We previously reported that crystallization of SSZ-13 zeolites in the presence of only TMAda $^{+}$cations produces a material with predominantly isolated framework $\mathrm{Al}$, reflected in the inability to exchange divalent $\mathrm{Co}^{2+}$ cations. ${ }^{39,40} \mathrm{~A}$ sample of SSZ-13 (Si/Al $=15$ ) was synthesized using this method and exchanged with different amounts of $\mathrm{Cu}^{2+}(\mathrm{Cu} / \mathrm{Al}=0.15,0.24)$ to generate two Cu-SSZ-13 samples of different ZCuOH density (sample preparation details and elemental analysis in ESI Section S2.1 and Table S4 $\dagger$ ).

After $\mathrm{Cu}^{2+}$ ion exchange, each model $\mathrm{ZCuOH}$ sample was treated in flowing oxygen at $673 \mathrm{~K}\left(20 \% \mathrm{O}_{2}\right.$, balance $\left.\mathrm{He}\right)$ for 120 min (details in ESI Section S2.2†). UV-Vis spectra of these Cu-SSZ-13 samples collected at $300 \mathrm{~K}$ are shown in Fig. $1 \mathrm{~b}$ and c. Spectra of both samples show absorbance features in the 8000 to $22000 \mathrm{~cm}^{-1}$ region that are centered around $\sim 11059$, 13593,16379 , and $20077 \mathrm{~cm}^{-1}$, and a shoulder in the 24000 to $30000 \mathrm{~cm}^{-1}$ range, and these features are higher in intensity for the sample with higher $\mathrm{Cu}$ content. These spectra are similar to those reported following similar pretreatments of $\mathrm{Cu}-\mathrm{SSZ}-13$ materials that are expected to contain predominantly $\mathrm{ZCuOH}$ species, ${ }^{18,48,50}$ by virtue of the $\mathrm{Na}^{+}$-free synthesis methods used 
(a)

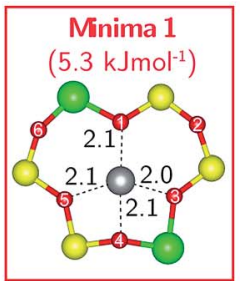

(b)

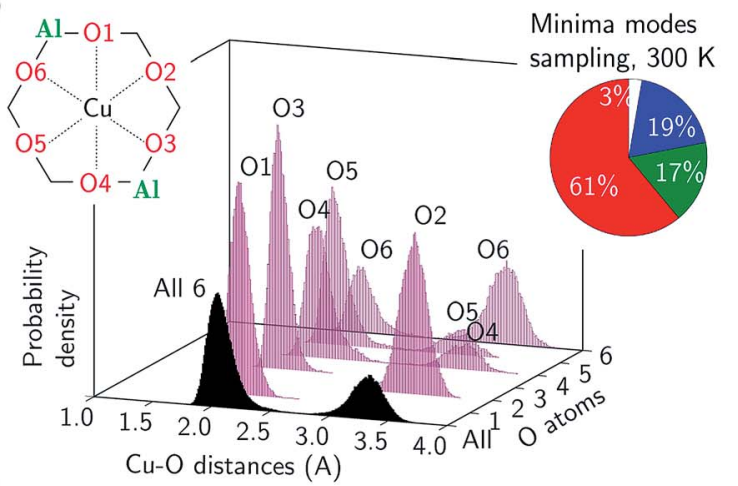

(c)

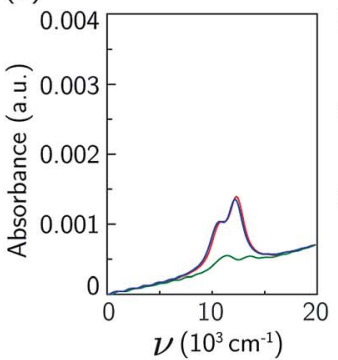

(d)

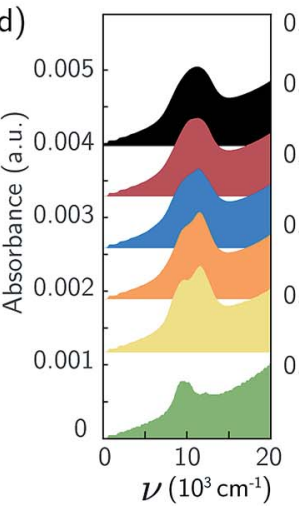

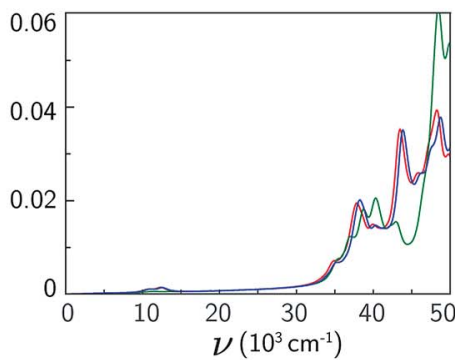
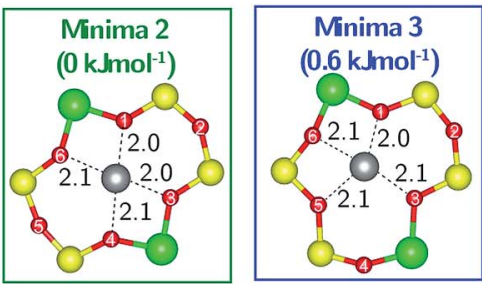

Minima modes pling, 300

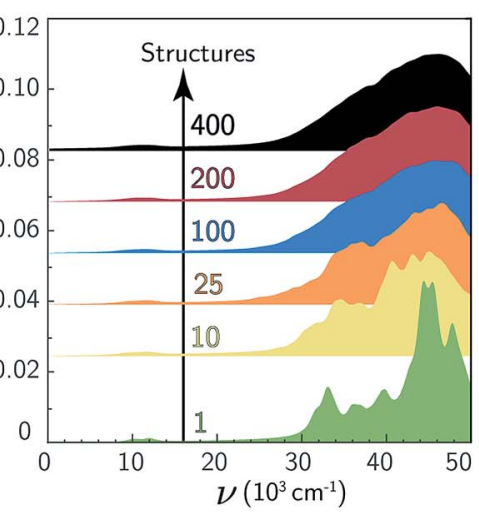

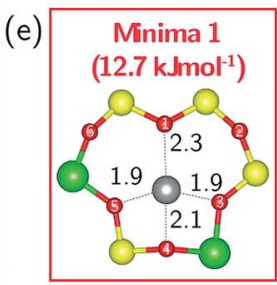
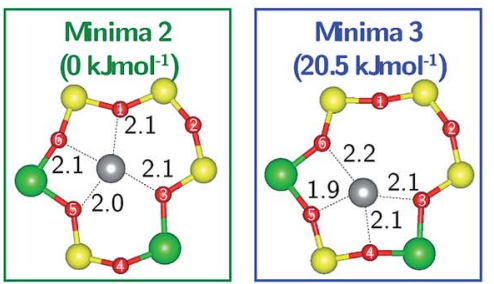

(f)

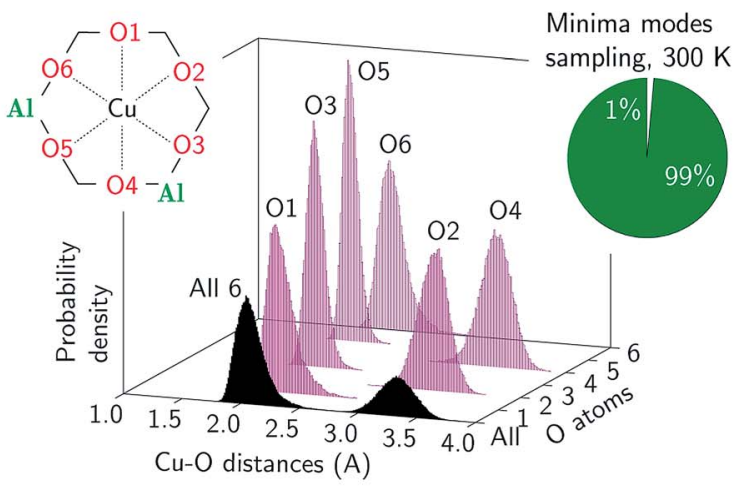

(g)
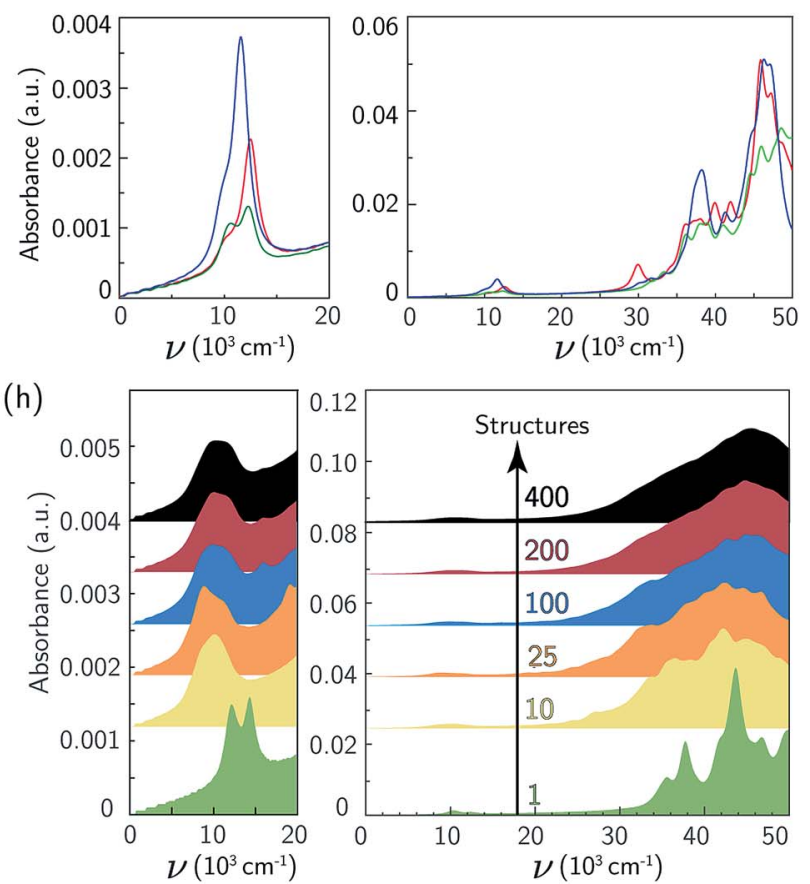

Fig. 2 (a) DFT-computed local Cu environment in three $\mathrm{Z}_{2} \mathrm{Cu}$ para minima. (b) Individual and aggregate para $\mathrm{Z}_{2} \mathrm{Cu} \mathrm{Cu}-\mathrm{O}_{\mathrm{f}}$ distance histograms collected over 150 ps $300 \mathrm{~K}$ AIMD. Inset indicates percent time spent in each minimum. (c) TD-DFT-computed UV-Vis spectra of three $Z_{2} C u$ para minima, color-coded by (a). (d) UV-Vis spectra averaged over 1 (green), 10 (yellow), 25 (orange), 100 (blue), 200 (red), and 400 (black) para Z ${ }_{2} C u$ snapshots equally spaced in time along the 150 ps trajectory. (e-h) Corresponding results for $\mathrm{Z}_{2} \mathrm{Cu}$ meta configuration.

to prepare the parent SSZ-13 sample. In contrast, these spectra are markedly different from those reported on materials expected to only contain $\mathrm{Z}_{2} \mathrm{Cu}$ species (Korhonen et al. ${ }^{6}$ and Fig. 1a). The four d-d transitions have different relative intensities in the two Cu-SSZ-13 samples shown in Fig. 1b and c. Literature Cu-SSZ-13 samples prepared to contain $\mathrm{ZCuOH}$ sites and exposed to the same $\mathrm{O}_{2}$ pre-treatment also share the same four $\mathrm{d}-\mathrm{d}$ transitions but again with different relative intensities. $^{\mathbf{1 8 , 4 8 , 5 0}}$ We conclude that a mononuclear $\mathrm{ZCuOH}$ species cannot be solely responsible for the quadruplet feature. The sample-dependent variation suggests the presence of additional multinuclear $\mathrm{ZCuOH}$-derived species with structures and populations that depend on synthesis, treatment and composition.

Da Costa et al. ${ }^{15}$ reported that $\mathrm{CO}$ reduces multinuclear $\mathrm{Cu}$ oxo species in Cu-ZSM-5 to isolated $\mathrm{Cu}^{+}\left(\mathrm{d}^{10}\right)$ ions that do not exhibit d-d transitions. Similarly, we hypothesize that multinuclear Cu-oxo species present in Cu-SSZ-13 samples after treatment in $\mathrm{O}_{2}$ at $673 \mathrm{~K}$ will be reduced by $\mathrm{CO}$ at $523 \mathrm{~K}$, leaving 
behind only isolated $\mathrm{ZCuOH}$ species and any residual $\mathrm{Z}_{2} \mathrm{Cu}$ sites. Model $\mathrm{Z}_{2} \mathrm{Cu}$ and $\mathrm{ZCuOH}$ samples were held in a flowing stream of $5 \% \mathrm{CO}$ at $523 \mathrm{~K}$ until no further changes in UV-Vis spectra were observed (details in ESI Section S2.4†), prior to sealing the UV-Vis cell and cooling to $300 \mathrm{~K}$ to record the spectra shown in Fig. 1, an approach similar to that applied by Ipek et al. to $\mathrm{Cu}-\mathrm{SSZ}-13$ samples containing mixtures of $\mathrm{Z}_{2} \mathrm{Cu}$ and $\mathrm{ZCuOH}$ sites. ${ }^{18}$ As expected, no changes were observed to the d$\mathrm{d}$ transition region in the spectrum of the $\mathrm{Z}_{2} \mathrm{Cu}$ sample upon $\mathrm{CO}$ exposure (Fig. 1a). In sharp contrast, the d-d features at 16379 and $20077 \mathrm{~cm}^{-1}$ and LMCT transition at $27000 \mathrm{~cm}^{-1}$ in the spectra of both ZCuOH samples (Fig. 1b and c) disappeared after exposure to $\mathrm{CO}$, and features at 11059 and $13593 \mathrm{~cm}^{-1}$ were shifted to 11350 and $13000 \mathrm{~cm}^{-1}$ and decrease markedly in absorbance. Despite differences in the $\mathrm{d}-\mathrm{d}$ quadruplet feature intensity that are detectable after high temperature $\mathrm{O}_{2}$ treatment, the $\mathrm{d}-\mathrm{d}$ transition features of both $\mathrm{ZCuOH}$ samples become similar after $\mathrm{CO}$ treatment. These findings indicate that not all $\mathrm{Cu}^{2+}$ sites in Cu-SSZ-13 are reducible to $\mathrm{Cu}^{+}$in the presence of $\mathrm{CO}$, that the $\mathrm{Cu}^{2+}$ sites remaining after $\mathrm{CO}$ reduction are similar for both samples (Fig. $1 \mathrm{~b}$ and $\mathrm{c}$, red), and that these signatures are of isolated $\mathrm{ZCuOH}$ sites.

We used the same triclinic supercell to describe a $[\mathrm{CuOH}]^{+}$ ion-exchanged near an isolated Al. Each T-site in the chabazite lattice is common to two $8 \mathrm{MR}$, one $6 \mathrm{MR}$, and three $4 \mathrm{MR}$. We used $473 \mathrm{~K}$ AIMD and geometry optimizations to compare the energies of the $[\mathrm{CuOH}]^{+}$ion in each of these orientations. The two $8 \mathrm{MR}$ orientations are isoenergetic and the $\mathrm{Cu}-\mathrm{X}(\mathrm{X}=\mathrm{Si}, \mathrm{Al}$, O) radial distribution function (RDF) computed from their AIMD trajectories are identical (ESI Fig. S6 $\dagger$ ). From a nudged elastic band calculation, the two 8MR minima are separated by a $63 \mathrm{~kJ} \mathrm{~mol}^{-1}$ barrier (ESI Fig. S7 $\dagger$ ). Similar calculations with the $[\mathrm{CuOH}]^{+}$ion directed into a $6 \mathrm{MR}$ and $4 \mathrm{MR}$ result in configurations 15 and $45 \mathrm{~kJ} \mathrm{~mol}^{-1}$ higher in energy. We thus expect $\mathrm{a}[\mathrm{CuOH}]^{+}$ion to adopt and remain in one of the $8 \mathrm{MR}$ orientations at typical conditions of observation here.

Again to explore the consequence of ion dynamics on spectroscopy, we performed additional AIMD simulations at $300 \mathrm{~K}$ for $150 \mathrm{ps}$ on a $[\mathrm{CuOH}]^{+}$ion in one of the $8 \mathrm{MR}$ orientations. During the course of the simulation the $\mathrm{Cu}$ ion remained coordinated to the same two $\mathrm{O}_{\mathrm{f}}$, bond distances fluctuated, and the $\mathrm{OH}$ ligand rotated between $\mathrm{Cu}-\mathrm{OH}$ rotational conformers twice. Fig. $3 \mathrm{~b}$ reports histograms of the two $\mathrm{Cu}-\mathrm{O}_{\mathrm{f}}$ and $\mathrm{Cu}-\mathrm{OH}$ distances. The $\mathrm{Cu}-\mathrm{OH}$ bond is shorter and has a narrower distribution than the $\mathrm{Cu}-\mathrm{O}_{\mathrm{f}}$ bond. The $\mathrm{Cu}-\mathrm{O}_{\mathrm{f}}$ mean distances are slightly shorter than those from the $\mathrm{Z}_{2} \mathrm{Cu}$ simulations while the standard deviations are the same as the $\mathrm{Z}_{2} \mathrm{Cu}$ trajectories (ESI Table S2 $\dagger$ ). Thus, the coordination environment around $\mathrm{ZCuOH}$ varies less than $\mathrm{Z}_{2} \mathrm{Cu}$. The inset to Fig. $3 \mathrm{~b}$ reports the fraction of the trajectory spent in each of the two rotational conformations.

The $8 \mathrm{MR}[\mathrm{CuOH}]^{+}$ion can exist in one of two rotational conformers that differ in energy by $6 \mathrm{~kJ} \mathrm{~mol}^{-1}$ and are distinguished by whether the $\mathrm{OH}$ ligand points into or out of the $8 \mathrm{MR}$ (Fig. 3a). Fig. 3c reports the computed UV-Vis spectra of a relaxed $8 \mathrm{MR}[\mathrm{CuOH}]^{+}$ion; each conformer yields a spectrum with two equivalent sharp features in the $\mathrm{d}-\mathrm{d}$ transition region (a)

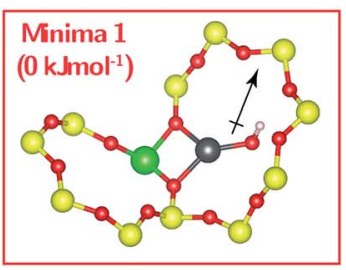

(b)

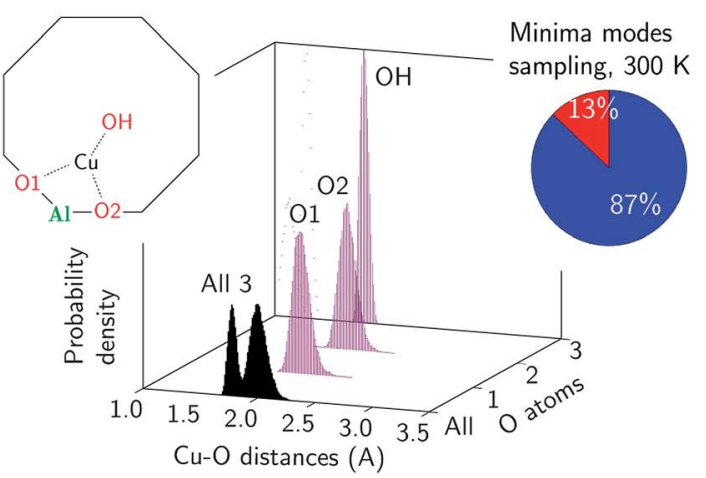

(c)

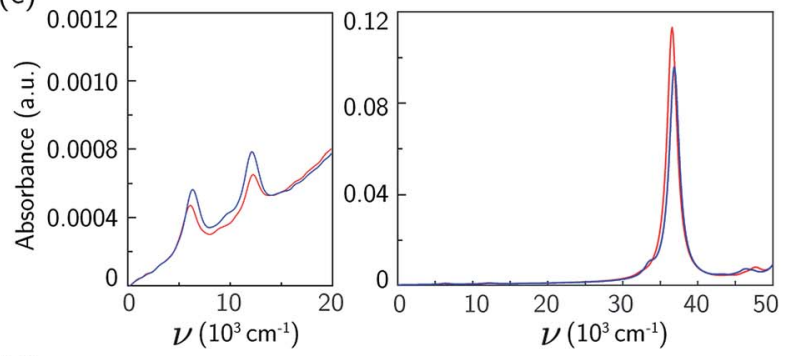

(d)

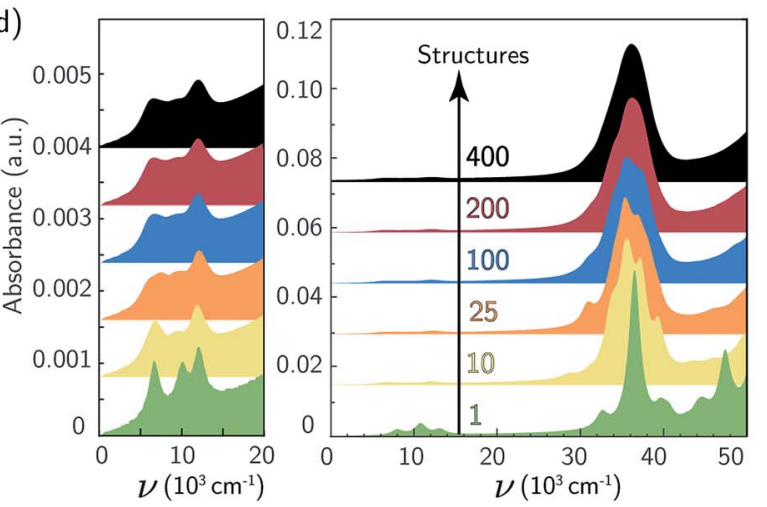

Fig. 3 (a) DFT-computed local Cu environment in two 8MR ZCuOH minima. (b) Individual and aggregate $\mathrm{Cu}-\mathrm{O}$ distance histograms collected over 150 ps of $300 \mathrm{~K}$ AIMD. Inset indicates percent time spent in each minimum. (c) TD-DFT-computed UV-Vis spectra of two ZCuOH minima, color-coded by (a). (d) UV-Vis spectra averaged over 1 (green), 10 (yellow), 25 (orange), 100 (blue), 200 (red), and 400 (black) snapshots equally spaced in time along the 150 ps trajectory.

and a single sharp LMCT band. Predicted $\mathrm{ZCuOH}$ absorption intensities are less than either the $\mathrm{Z}_{2} \mathrm{Cu}$ para and meta spectra in Fig. $2 \mathrm{c}$ and g, consistent with the higher symmetry of $\mathrm{ZCuOH}$ and prior predictions that $\mathrm{ZCuOH}$ may have small or unobservable d-d transitions. ${ }^{49,74}$ However the two spectra in Fig. $3 \mathrm{c}$ for the two $\mathrm{ZCuOH}$ isomers are only in rough correspondence with the observed spectrum of the $\mathrm{ZCuOH}$ samples.

We computed the absorption spectra of 400 equally spaced structures chosen from the $300 \mathrm{~K}$ AIMD simulation; all 
computed spectra are overlaid in Fig. S4c. $\dagger$ Significant variations are present in the $\mathrm{d}-\mathrm{d}\left(7000\right.$ to $\left.14000 \mathrm{~cm}^{-1}\right)$ and LMCT (30 000 to $50000 \mathrm{~cm}^{-1}$ ) regions (ESI Fig. S6c $\dagger$ ), with shorter mean $\mathrm{Cu}-\mathrm{O}$ distances again correlating with shifts to higher frequency $d-d$ transitions (ESI Fig. S5 $\dagger$ ). Fig. $3 d$ reports spectra averaged over 1, 10, 25, 100, 200, and 400 structures. The two sharp d-d features at 8000 and $13000 \mathrm{~cm}^{-1}$ broaden and begin to merge, while the LMCT region converges to a peak spanning 30000 to $45000 \mathrm{~cm}^{-1}$. The averaged d-d and LMCT regions $\approx 1000 \mathrm{~cm}^{-1}$ are red-shifted but similar in shape to those observed after $\mathrm{CO}$ reduction of the $\mathrm{ZCuOH}$ samples (Fig. $1 \mathrm{~b}$ and c). Further, the decrease in computed intensity of the d-d relative to LMCT bands in $\mathrm{ZCuOH}$ compared to $\mathrm{Z}_{2} \mathrm{Cu}$ models corresponds with experimental observation. These observations support both the assignment of the Fig. 1b and c spectra following $\mathrm{CO}$ treatment (red) to isolated $\mathrm{ZCuOH}$ and the conclusion that the quadruplet features after $\mathrm{O}_{2}$ treatment (black) cannot be solely assigned to $\mathrm{ZCuOH}$ but rather have contributions from multinuclear $\mathrm{Cu}$ complexes.

\subsection{Cu dimers}

The additional features in Fig. $1 \mathrm{~b}$ and c following $673 \mathrm{~K} 20 \% \mathrm{O}_{2}$ treatment are from CO-reducible $\mathrm{Cu}$ species. A discrete, exchanged $[\mathrm{CuO}]^{+}$ion is an unlikely candidate because it has a unfavorable computed formation free energy and its computed spectrum (ESI Fig. S8 $\dagger$ ) is inconsistent with experimental observation. More likely are dimeric or larger $\mathrm{Cu}$ clusters. To test the potential for isolated $\mathrm{ZCuOH}$ to condense into dimers, we considered two $[\mathrm{CuOH}]^{+}$ions located at $\mathrm{Al}$ separated by four T-sites in the same 8-MR using a 36-T-site supercell. Fig. 4a, structures $\mathrm{C}$ and $\mathrm{E}$ show the $\mathrm{ZCu}(\mathrm{OH})_{2} \mathrm{CuZ}$ condensation product and of its $\mathrm{ZCuOCuZ}$ dehydration product, respectively (details in ESI Section S1.12 and Fig. S9†). Within the generalized gradient and harmonic approximations, the free energies to form $\mathrm{ZCu}(\mathrm{OH})_{2} \mathrm{CuZ}$ and dehydrate to $\mathrm{ZCuOCuZ}$ are computed to be -108 and $-116 \mathrm{~kJ} \mathrm{~mol}^{-1}$, respectively (details in ESI Section S1.12†). These energetics are consistent with the formation of dimers from $[\mathrm{CuOH}]^{+}$ions of suitable proximity.

We performed $150 \mathrm{ps}$ AIMD at $300 \mathrm{~K}$ on these two dimer structures in the 12-T-site supercell. In both trajectories the dimers remain roughly in the plane of the $8 \mathrm{MR}$ and retain coordination to the same bridging and framework $\mathrm{O}$, unlike the more dynamic $\mathrm{Z}_{2} \mathrm{Cu}$ behavior described above. Both dimers vibrate internally and against the framework. Histograms of the $\mathrm{Cu}-\mathrm{O}$ and $\mathrm{Cu}-\mathrm{Cu}$ distances are shown in Fig. $4 \mathrm{~b}$ and c. In ZCuOCuZ, $\mathrm{Cu}-\mathrm{O}_{\mathrm{b}}$ (bridging $\mathrm{O}$ ) distances are systematically shorter and fluctuate less than $\mathrm{Cu}-\mathrm{O}_{\mathrm{f}}$. The $\mathrm{Cu}-\mathrm{Cu}$ separation oscillates around $2.7 \AA$, and $\mathrm{Cu}-\mathrm{O}-\mathrm{Cu}$ angle varies from 90 to $115^{\circ}$. The $\mathrm{Cu}(\mathrm{OH})_{2}$ core of $\mathrm{ZCu}(\mathrm{OH})_{2} \mathrm{CuZ}$ remains essentially planar and tilted at an angle of $\approx 35^{\circ}$ with respect to the $8 \mathrm{MR}$ plane during the AIMD (structure in ESI Fig. S12†). The $\mathrm{Cu}-$ $\mathrm{O}_{\mathrm{b}}(\mathrm{H})$ and $\mathrm{Cu}-\mathrm{O}_{\mathrm{f}}$ distances cover a similar range, and the $\mathrm{Cu}-\mathrm{Cu}$ separation oscillates around $3 \AA$.

We used TD-DFT and spectral averaging methods identical to those above to simulate UV-Vis spectra of both dimers at 300 $\mathrm{K}$. We observed computed spectra to be sensitive to the geometries of the dimers, similar to the monomer $\mathrm{Z}_{2} \mathrm{Cu}$ and $\mathrm{ZCuOH}$. Fig. S10 $\dagger$ shows spectra averaged over various numbers of snapshots; spectral averaging converge after $\approx 200$ structures. Fig. 4d shows the spectra averaged over 400 snapshots. The spectrum of $\mathrm{ZCu}(\mathrm{OH})_{2} \mathrm{CuZ}$ structure (C) exhibits a broad and low intensity $\mathrm{d}-\mathrm{d}$ feature around $12400 \mathrm{~cm}^{-1}$ and a LMCT band blue-shifted to beyond $50000 \mathrm{~cm}^{-1}$. In contrast, the spectrum of $\mathrm{ZCuOCuZ}$ structure (E) has two distinct $\mathrm{d}-\mathrm{d}$ features around
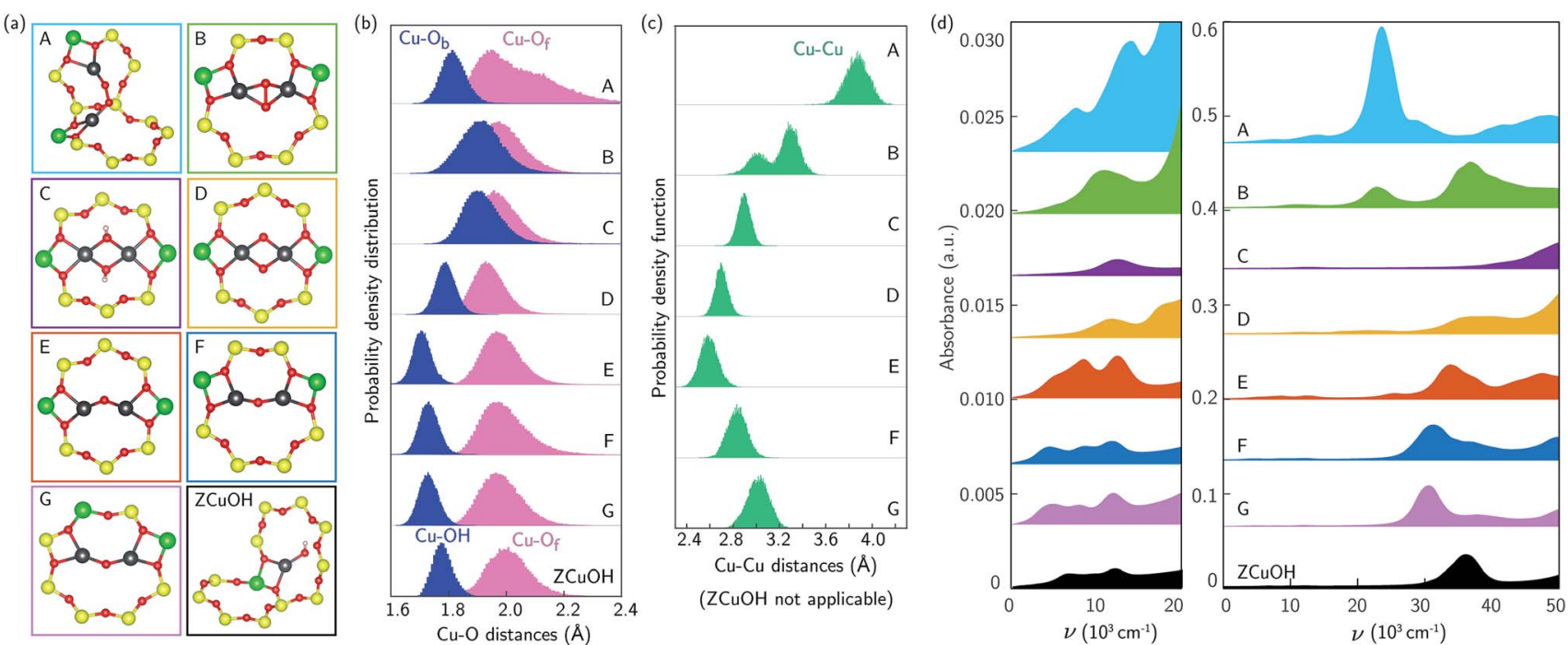

Fig. 4 (a) Optimized geometries of $\mathrm{Cu}$ dimers $\mathrm{A}-\mathrm{G}$, and $\mathrm{ZCuOH}$ for reference. (b)/(c) Aggregate $\mathrm{Cu}-\mathrm{O}$ distance (b) and $\mathrm{Cu}-\mathrm{Cu}$ distance (c) histograms for dimers $A-G$ and $Z \mathrm{CuOH}$ collected over 150 ps $300 \mathrm{~K}$ AIMD. Bridging $\mathrm{O}_{\mathrm{b}}$ and $\mathrm{OH}$ distances are presented in blue, $\mathrm{O}_{\mathrm{f}}$ distances are in pink, $\mathrm{Cu}-\mathrm{Cu}$ distances are in green. (d) Averaged spectra of $\mathrm{Cu}$ dimers A-G (left panel is from $0-20000 \mathrm{~cm}^{-1}$, right panel is from 0 to $50000 \mathrm{~cm}^{-1}$, each spectra is offset on the $y$-axis). Colors of spectra are consistent with those in (a). Averaged ZCuOH spectrum is plotted at the bottom in black for reference. 
8500 and $12400 \mathrm{~cm}^{-1}$ and an LMCT band edge that begins near $30000 \mathrm{~cm}^{-1}$. These two are clearly distinct from one another and from the computed spectrum of $\mathrm{ZCuOH}$.

The spectroscopy of $\mathrm{Cu}$ dimers may be sensitive to $\mathrm{Al}$ proximity, through its influence on geometric and electronic structures. To test this effect, we constructed two additional ZCuOCuZ models with two $\mathrm{Al}$ placed third- and second-nearestneighbor in an $8 \mathrm{MR}$ and introduced a $\mathrm{Cu}-\mathrm{O}-\mathrm{Cu}$ dimer so as to maintain $\mathrm{Cu}-\mathrm{O}$ distances and a $\mathrm{Cu}-\mathrm{O}-\mathrm{Cu}$ angle similar to previous reports. ${ }^{11,18}$ Fig. 4a shows the optimized structures $\mathrm{F}$ and $\mathrm{G}$ used to initiate subsequent dynamics. At $3 \mathrm{NN}$, the $\mathrm{ZCuOCuZ}$ dimer is symmetrically coordinated to $\mathrm{O}_{\mathrm{f}}$ associated with $\mathrm{Al}$; at $2 \mathrm{NN}$, this symmetry is broken, although both $\mathrm{Cu}$ remain bound to two $\mathrm{O}_{\mathrm{f}}$. During subsequent $300 \mathrm{~K}$ AIMD simulations the $\mathrm{Cu}$ ions retain their coordination; as shown in the histograms, $\mathrm{Cu}-\mathrm{O}$ distances vary across the same ranges at all $\mathrm{Al}$ placements while $\mathrm{Cu}-\mathrm{Cu}$ distances and $\mathrm{Cu}-\mathrm{O}-\mathrm{Cu}$ angles vary considerably with $\mathrm{Al}$ separation. While the computed spectra of the optimized structures are different, these differences largely disappear during averaging. As shown in Fig. 4d, averaged spectra have similar $\mathrm{d}-\mathrm{d}$ features and differ only in the LMCT band edge position.

The $\mathrm{Cu}$ dimer spectroscopy could also be sensitive to geometric isomerism. To test this effect, we considered several examples of $\mathrm{Cu}$ dimers bridged by two $\mathrm{O}$, a well known motif that exhibits several geometric isomers that are sensitive to $\mathrm{Al}$ separation. ${ }^{34,74-76}$ Fig. 4a structures A, B, and D correspond to three different $\mathrm{Al}$ placements and three different isomers, all of which were obtained by geometry relaxations beginning from literature structures. ${ }^{\mathbf{1 1 , 1 8}} \mathrm{A}$ and $\mathrm{B}$ have triplet and D has a singlet ground states, consistent with earlier results. ${ }^{34,75}$ Computed spectra at the optimized geometries (ESI Fig. S10†) exhibit sharp and distinct peaks in both the $\mathrm{d}-\mathrm{d}$ and LMCT regions. We performed AIMD on all three isomers; distance histograms collected during the simulations are shown in Fig. $4 \mathrm{~b}$ and c. The dioxo dimer $\mathrm{D}$ is the least variable across the trajectory; dimers $\mathrm{A}$ and $\mathrm{B}$ sample much larger $\mathrm{Cu}-\mathrm{O}_{\mathrm{f}}$ and $\mathrm{Cu}-\mathrm{Cu}$ distances, respectively. During the finite temperature simulation, dimer $\mathrm{A}$ moves from a cis to a trans $\mu$-peroxo orientation whereas the optimized geometry has a slightly twisted O-O linkage, resulting in smaller $\mathrm{Cu}-\mathrm{O}-\mathrm{O}$ angles (geometry comparison in ESI Fig. $\mathrm{S} 13 \dagger$ ). Fig. $4 \mathrm{~d}$ reports computed spectra averaged over 400 snapshots. Spectra differ significantly in band location and intensity both in the $\mathrm{d}-\mathrm{d}$ and LMCT regions.

UV-Vis spectra are thus sensitive to $\mathrm{Cu}$ dimer composition and structure and dynamics. Comparisons with the experimental spectra collected after $20 \% \mathrm{O}_{2}$ treatment at $673 \mathrm{~K}$ in Fig. $1 \mathrm{~b}$ and $\mathrm{c}$ are complicated by the ill-defined number and nuclearity of $\mathrm{Cu}$ species present in the samples. Nevertheless, we can make some useful connections. The relative intensities of the $\mathrm{d}-\mathrm{d}$ transitions for some dimeric $\mathrm{Cu}$ species (in particular $\mathrm{A}, \mathrm{B}$, and $\mathrm{E}$ ) are computed to be greater than that of monomeric $\mathrm{ZCuOH}$, consistent with the observation of decreases in dd peak intensity following CO reduction. Structures B, E, and F have features that roughly correspond with those observed at 11 059, 13 593, 16 379, and $20077 \mathrm{~cm}^{-1}$ (Fig. 1b and c), but redshifted by an amount similar to that found in the comparison of computed and observed $\mathrm{ZCuOH}$ spectra. Structures $\mathrm{C}$ and $\mathrm{D}$ contain features that are plausible candidates for the features observed at 16000 and $19000 \mathrm{~cm}^{-1}$. Structures A and B contain features that could account for the broad low energy LMCT shoulder from $\approx 22000$ to $27000 \mathrm{~cm}^{-1}$ that disappears after the $\mathrm{CO}$ reduction treatment. All these results imply that the variations in the quadruplet feature in the $\mathrm{d}-\mathrm{d}$ region of nominally $\mathrm{ZCuOH}$ samples shown in Fig. $3 \mathrm{~b}$ and $\mathrm{c}$ are associated at least in part with the contributions of different numbers and/or types of dimers from sample to sample.

\section{Discussion}

Cu-SSZ-13 samples used here and reported in the literature are now well understood to be intrinsically heterogeneous at the microscopic scale, as a result of variations in composition and location of $\mathrm{Al}^{77}$ and charge-compensating $\mathrm{Cu}$ ions, among other factors. Some of these differences are readily observed spectroscopically; for instance $\mathrm{ZCuOH}$ sites are clearly indicated by their distinctive $\mathrm{O}-\mathrm{H}$ stretch vibration at $3660 \mathrm{~cm}^{-1}, 38,78,79$ while others are more subtle to infer. The UV-Vis results reported here provide some guidance for distinguishing three types of $\mathrm{Cu}$ species. $\mathrm{Z}_{2} \mathrm{Cu}$ species are distinguished by relatively intense $\mathrm{d}-$ d transitions with maxima near 12000 and $14000 \mathrm{~cm}^{-1}$ (Fig. 1a), and these features persist upon exposure to CO. Isolated $\mathrm{ZCuOH}$ species are indicated by lower intensity dd features near 11000 and $13000 \mathrm{~cm}^{-1}$, which also persist during exposure to $\mathrm{CO}$. We find that samples intentionally prepared to contain exclusively $\mathrm{ZCuOH}$ always contain a confounding set of species that have relatively intense but irregular $\mathrm{d}-\mathrm{d}$ features, which we assign to a mixture of higher nuclearity $\mathrm{Cu}$ oxo and hydroxo species. These species contribute four relatively prominent features in the $\mathrm{d}-\mathrm{d}$ region, but they do not persist following CO reduction treatments.

Discrimination within these sets is more challenging. Samples prepared to contain only $\mathrm{Z}_{2} \mathrm{Cu}$ species potentially contain two geometrically distinct sites distinguished by the location of the charge-compensating $\mathbf{A l},{ }^{\mathbf{8 0}}$ and such sites are predicted here to have distinct UV-Vis spectra if computed at one minimum energy structure. Accounting for the finite temperature fluctuations in $\mathrm{Cu}$ location between local minima and associated fluctuations in $\mathrm{Cu}$ coordination environment, however, attenuates these differences, such that the two sites become spectroscopically indistinguishable. Similar factors affect the interpretation of XAS, ${ }^{79,81-84} \mathrm{EPR}^{\mathbf{4 9 , 8 3 , 8 5}}$ spectroscopies, and X-ray diffraction ${ }^{5,82,85,86}$ patterns, and caution should be applied in inferring $\mathrm{Z}_{2} \mathrm{Cu}$ geometric information by comparison of observations to predictions from single, minimum energy structures.

In samples in which $\mathrm{Cu}$ exchange is predominantly associated with isolated $\mathrm{Al}$ T-sites and contain a majority of $\mathrm{ZCuOH}$ sites, observed UV-Vis spectra contain features in the $\mathrm{d}-\mathrm{d}$ and LMCT regions that cannot be accounted for by the spectrum computed of these sites. ${ }^{\mathbf{1 8 , 4 8 , 4 9 , 8 7}}$ Strategies to directly prepare and characterize $\mathrm{Cu}-\mathrm{SSZ}-13$ samples that contain exclusively $\mathrm{ZCuOH}$ sites, either by exchanging dilute amounts of $\mathrm{Cu}$ or using higher silica-content SSZ-13 supports, are unlikely to be 
successful because of the difficulties of observing dilute $\mathrm{ZCuOH}$ and the presence of a confounding set of framework $\mathrm{Al}$ sites that can stabilize dimeric forms of $\mathrm{Cu}$ even at low $\mathrm{Al}$ density. Therefore, a strategy that combines synthetic efforts to bias formation of predominantly one $\mathrm{Cu}$ site type with treatments that selectively remove minority $\mathrm{Cu}$ species, is more likely to allow access to individual $\mathrm{Cu}$ site types.

The exact shapes and positions of the features depend on the zeolite composition and the precise pretreatment conditions, including temperature, pressure and duration of $\mathrm{O}_{2}$ exposure, all suggestive of additional $\mathrm{Cu}$ sites produced dynamically. Calculations here show that $[\mathrm{CuOH}]^{+}$ions can move between adjacent 8MRs with an activation barrier of $63 \mathrm{~kJ} \mathrm{~mol}^{-1}$ (ESI Fig. $\mathrm{S} 7 \dagger$ ) and that suitably proximal ions can condense into dimers. This proposal is consistent with experimental observations of a decrease in the approximately $3660 \mathrm{~cm}^{-1}$ vibrational feature associated with the $\mathrm{ZCuO}-\mathrm{H}$ stretch with increasing temperature, ${ }^{41}$ corresponding Raman shifts for multiple $\mathrm{Cu}_{2} \mathrm{O}_{x}$ motifs. ${ }^{18,19,55}$ It is also consistent with the observation of dry $\mathrm{NO}$ oxidation to $\mathrm{NO}_{2}$ on nominally $\mathrm{ZCuOH}-$ containing samples, ascribed to dimeric $\mathrm{Cu}$ sites. ${ }^{11,88}$ Because computed UV-Vis spectra of $\mathrm{Cu}$ dimers (Fig. 4) are sensitive to $\mathrm{Al}$ proximity, extra-lattice ligands, and to finite temperature structural fluctuations, assignment of specific spectroscopic features to individual types of dimeric $\mathrm{Cu}$ species is not possible based on results reported here.

The samples prepared to contain $\mathrm{Z}_{2} \mathrm{Cu}$ sites have spectral features that are invariant to reduction in CO. Literature results on similar samples find that they are insensitive to exposure to $\mathrm{He}, \mathrm{O}_{2}$, or $\mathrm{CH}_{4} \cdot{ }^{6,19}$ The four features observed in the $\mathrm{d}-\mathrm{d}$ region of the $\mathrm{ZCuOH}$ samples following oxidizing treatment are similar to those reported previously in similar samples, ${ }^{\mathbf{1 8 , 4 8 , 5 0}}$ but these bands do respond differently to subsequent reducing treatments. We find that $5 \% \mathrm{CO}$ exposure at $523 \mathrm{~K}$ reproducibly preserves a portion of the $\mathrm{d}-\mathrm{d}$ and LMCT features, which we assign to isolated $\mathrm{ZCuOH}$ sites. In contrast, exposure to $\mathrm{CH}_{4}$ at $473 \mathrm{~K}$ results only in a decrease in the lower energy portion (25 000 to $38000 \mathrm{~cm}^{-1}$ ) of the LMCT band and disappearance of the $29000 \mathrm{~cm}^{-1}$ band. ${ }^{\mathbf{1 8 , 5 0 , 8 7}}$ These results suggest that the same temperature $\mathrm{CH}_{4}$ reduces a different population of $\mathrm{Cu}_{x}$ $\mathrm{O}_{y} \mathrm{H}_{z}$ moieties to $\mathrm{Cu}^{+}$than exposure to inert $(\mathrm{He})$, and exposure to $\mathrm{CO}$ reduces all of the $\mathrm{Cu}_{x} \mathrm{O}_{y} \mathrm{H}_{z}$ observed to reduce in either $\mathrm{CH}_{4}$ or $\mathrm{He}^{18}$ Spectral features we assign here to isolated $\mathrm{ZCuOH}$ moieties are observed in similar materials to persist after $\mathrm{CH}_{4}$ exposure. ${ }^{18,50}$ Precise identification of the $\mathrm{Cu}$ dimer sites responsible for $\mathrm{CH}_{4}$ activation under different conditions remains an important challenge for experiment and computation.

\section{Conclusions}

$\mathrm{Cu}$-exchanged zeolites remain a topic of great scientific interest because of their intriguing performance in catalyzing difficult transformations involving the nitrogen oxides and methane. Identification of active sites is complicated by the sensitivity of $\mathrm{Cu}$ exchange to zeolite framework types, the number and distribution of framework $\mathrm{Al}$ atoms, $\mathrm{Cu}$ content, and pretreatment conditions. The SSZ-13 zeolite framework is constructed of a single symmetry-distinct type of T-site, in principle reducing the number of possible distinct ion exchange sites and thus simplifying spectroscopic interrogation of those sites. Here we use directed synthetic approaches to emphasize different types of exchange sites, and DFT evaluations of site structure and spectral signatures to test this principle. We find that in SSZ-13 samples prepared to contain only isolated Al T-sites, and thus in principle a homogeneous array of $[\mathrm{CuOH}]^{+}$ion exchange sites, always contain a confounding subset of $\mathrm{O}$ - or $\mathrm{OH}$-bridged $\mathrm{Cu}$ dimers and/or larger aggregates in the $\mathrm{Cu} / \mathrm{Al}$ exchange regime explored here. These latter species are intrinsically heterogeneous due to heterogeneity in bridging ligands and/or in arrangements of framework Al substituents, which likely involve more than one $\mathrm{Al} \mathrm{T}$-site. The underlying $[\mathrm{CuOH}]^{+} \mathrm{UV}-\mathrm{Vis}$ spectrum can be revealed by selective CO reduction of the polynuclear $\mathrm{Cu}$ species. The UV-Vis spectrum, even of isolated $[\mathrm{CuOH}]^{+}$ions, is found to be influenced by the intrinsic, finitetemperature dynamics of the site, as revealed through AIMD and TD-DFT calculations. In SSZ-13 samples prepared to contain $2 \mathrm{NN}$ (meta) and $3 \mathrm{NN}$ (para) Al pairs in the 6MR, the same dynamical factors serve to obscure spectroscopic differences between these two distinct types of $\mathrm{Z}_{2} \mathrm{Cu}$ sites. While calculations performed at the optimized geometries predict that the meta and para $\mathrm{Cu}$-exchange sites are spectroscopically distinct, those differences are indistinguishable after accounting for the finite-temperature fluctuations in $\mathrm{Cu}$ ion coordination environment.

These results highlight the potential and the practical challenges of developing correlations between observed spectroscopy and the contributions of various $\mathrm{Cu}$ ion exchange sites and motifs to observed chemical reactivity. They highlight that precise characterization of active sites in this and similar systems demands a careful integration of chemical and spectroscopic interrogation with computational models that account for the structural and dynamical complexities of the materials.

\section{Conflicts of interest}

There are no conflicts to declare.

\section{Acknowledgements}

The experimental research at Purdue on zeolite synthesis and characterization was supported by the U.S. Department of Energy, Office of Science, Office of Basic Energy Sciences, under Award Number DE-SC0019026. The computational work at Notre Dame was supported by the National Science Foundation GOALI program under award number CBET-1258690. We thank the Center for Research Computing at Notre Dame, and EMSL, a DOE Office of Science User Facility sponsored by the Office of Biological and Environmental Research and located at Pacific Northwest National Laboratory, for support of computational resources. We thank John R. Di Iorio (Purdue) for assistance with zeolite synthesis and helpful technical discussions. Florian 
Göltl contributions were supported in part through NSF grant number CHE-1800284.

\section{References}

1 C. Paolucci, J. Di Iorio, F. Ribeiro, R. Gounder and W. Schneider, Adv. Catal., 2016, 59, 1-107.

2 A. M. Beale, F. Gao, I. Lezcano-Gonzalez, C. H. Peden and J. Szanyi, Recent advances in automotive catalysis for $\mathrm{NO}_{x}$ emission control by small-pore microporous materials, Chem. Soc. Rev., 2015, 44, 7371-7405.

3 F. Gao, J. H. Kwak, J. Szanyi and C. H. Peden, Current understanding of $\mathrm{Cu}$-exchanged chabazite molecular sieves for use as commercial diesel engine DeNO $_{x}$ catalysts, Top. Catal., 2013, 56, 1441-1459.

4 I. Nova and E. Tronconi, Urea-SCR technology for deNO $\mathrm{N}_{x}$ after treatment of diesel exhausts, Springer, 2014.

5 D. W. Fickel and R. F. Lobo, Copper coordination in Cu-SSZ13 and Cu-SSZ-16 investigated by variable-temperature XRD, J. Phys. Chem. C, 2010, 114, 1633-1640.

6 S. T. Korhonen, D. W. Fickel, R. F. Lobo, B. M. Weckhuysen and $\mathrm{A}$. M. Beale, Isolated $\mathrm{Cu}^{2+}$ ions: active sites for selective catalytic reduction of NO, Chem. Commun., 2011, 47, 800802.

7 A. Marberger, A. W. Petrov, P. Steiger, M. Elsener, O. Kröcher, M. Nachtegaal and D. Ferri, Time-resolved copper speciation during selective catalytic reduction of NO on Cu-SSZ-13, Nat. Catal., 2018, 1, 221-227.

8 T. V. Janssens, H. Falsig, L. F. Lundegaard, P. N. Vennestrøm, S. B. Rasmussen, P. G. Moses, F. Giordanino, E. Borfecchia, K. A. Lomachenko and C. Lamberti, A consistent reaction scheme for the selective catalytic reduction of nitrogen oxides with ammonia, ACS Catal., 2015, 5, 2832-2845.

9 K. A. Lomachenko, E. Borfecchia, C. Negri, G. Berlier, C. Lamberti, P. Beato, H. Falsig and S. Bordiga, The $\mathrm{Cu}-$ CHA deNO ${ }_{x}$ Catalyst in Action: Temperature-Dependent $\mathrm{NH}_{3}$-Assisted Selective Catalytic Reduction Monitored by Operando XAS and XES, J. Am. Chem. Soc., 2016, 138, 12025-12028.

10 J. H. Kwak, R. G. Tonkyn, D. H. Kim, J. Szanyi and C. H. Peden, Excellent activity and selectivity of Cu-SSZ-13 in the selective catalytic reduction of $\mathrm{NO}_{x}$ with $\mathrm{NH}_{3}, J$. Catal., 2010, 275, 187-190.

11 A. A. Verma, S. A. Bates, T. Anggara, C. Paolucci, A. A. Parekh, K. Kamasamudram, A. Yezerets, J. T. Miller, W. N. Delgass, W. F. Schneider and F. H. Ribeiro, NO oxidation: A probe reaction on Cu-SSZ-13, J. Catal., 2014, 312, 179-190.

12 M. P. Ruggeri, I. Nova, E. Tronconi, J. A. Pihl, T. J. Toops and W. P. Partridge, In situ DRIFTS measurements for the mechanistic study of NO oxidation over a commercial $\mathrm{Cu}-$ CHA catalyst, Appl. Catal., B, 2015, 166, 181-192.

13 G. Centi and S. Perathoner, Nature of active species in copper-based catalysts and their chemistry of transformation of nitrogen oxides, Appl. Catal., A, 1995, 132, 179-259.

14 M. H. Groothaert, J. A. Van Bokhoven, A. A. Battiston, B. M. Weckhuysen and R. A. Schoonheydt, Bis( $\mu$-oxo) dicopper in Cu-ZSM-5 and its role in the decomposition of NO: A combined in situ XAFS, UV-vis-near-IR, and kinetic study, J. Am. Chem. Soc., 2003, 125, 7629-7640.

15 P. Da Costa, B. Moden, G. D. Meitzner, D. K. Lee and E. Iglesia, Spectroscopic and chemical characterization of active and inactive $\mathrm{Cu}$ species in NO decomposition catalysts based on Cu-ZSM5, Phys. Chem. Chem. Phys., 2002, 4, 4590-4601.

16 P. Vanelderen, J. Vancauwenbergh, B. F. Sels and R. A. Schoonheydt, Coordination chemistry and reactivity of copper in zeolites, Coord. Chem. Rev., 2013, 257, 483-494.

17 M. J. Wulfers, R. F. Lobo, B. Ipek and S. Teketel, Conversion of Methane to Methanol on Copper-Containing Small-Pore Zeolites and Zeotypes, Chem. Commun., 2015, 51, 4447-4450.

18 B. Ipek, M. J. Wulfers, H. Kim, F. Göltl, I. Hermans, J. P. Smith, K. S. Booksh, C. M. Brown and R. F. Lobo, Formation of $\left[\mathrm{Cu}_{2} \mathrm{O}_{2}\right]^{2+}$ and $\left[\mathrm{Cu}_{2} \mathrm{O}\right]^{2+}$ toward $\mathrm{C}-\mathrm{H}$ Bond Activation in Cu-SSZ-13 and Cu-SSZ-39, ACS Catal., 2017, 7, 4291-4303.

19 D. K. Pappas, et al., Methane to Methanol: Structure-Activity Relationships for Cu-CHA, J. Am. Chem. Soc., 2017, 139, 14961-14975.

20 A. R. Kulkarni, Z. Zhao, S. Siahrostami, J. K. Nørskov and F. Studt, Cation-Exchanged Zeolites for the Selective Oxidation of Methane to Methanol, Catal. Sci. Technol., 2017, 8, 114-123.

21 P. Tomkins, A. Mansouri, S. E. Bozbag, F. Krumeich, M. B. Park, E. M. C. Alayon, M. Ranocchiari and J. A. van Bokhoven, Isothermal Cyclic Conversion of Methane into Methanol over Copper-Exchanged Zeolite at Low Temperature, Angew. Chem., Int. Ed., 2016, 55, 5467-5471.

22 J. S. Woertink, P. J. Smeets, M. H. Groothaert, M. A. Vance, B. F. Sels, R. A. Schoonheydt and E. I. Solomon, A $\left[\mathrm{Cu}_{2} \mathrm{O}\right]^{2+}$ core in Cu-ZSM-5, the active site in the oxidation of methane to methanol, Proc. Natl. Acad. Sci. U. S. A., 2009, 106, 18908-18913.

23 S. Grundner, M. A. C. Markovits, G. Li, M. Tromp, E. A. Pidko, E. J. M. Hensen, A. Jentys, M. Sanchez-Sanchez and J. A. Lercher, Single-site trinuclear copper oxygen clusters in mordenite for selective conversion of methane to methanol, Nat. Commun., 2015, 6, 7546.

24 E. Borfecchia, P. Beato, S. Svelle, U. Olsbye, C. Lamberti and $\mathrm{S}$. Bordiga, $\mathrm{Cu}-\mathrm{CHA}$ - a model system for applied selective redox catalysis, Chem. Soc. Rev., 2018, 47, 8097-8133.

25 M. Dusselier and M. E. Davis, Small-Pore Zeolites: Synthesis and Catalysis, Chem. Rev., 2018, 118, 5265-5329.

26 B. E. Snyder, M. L. Bols, R. A. Schoonheydt, B. F. Sels and E. I. Solomon, Iron and Copper Active Sites in Zeolites and Their Correlation to Metalloenzymes, Chem. Rev., 2017, 118, 2718-2768.

27 K. T. Dinh, M. M. Sullivan, P. Serna, R. J. Meyer, M. Dincă and Y. Román-Leshkov, Viewpoint on the Partial Oxidation of Methane to Methanol Using $\mathrm{Cu}$ - and Fe-Exchanged Zeolites, ACS Catal., 2018, 8, 8306-8313.

28 A. A. Latimer, A. R. Kulkarni, H. Aljama, J. H. Montoya, J. S. Yoo, C. Tsai, F. Abild-Pedersen, F. Studt and J. K. Nørskov, Understanding trends in $\mathrm{C}-\mathrm{H}$ bond 
activation in heterogeneous catalysis, Nat. Mater., 2017, 16, 225.

29 A. R. Kulkarni, Z.-J. Zhao, S. Siahrostami, J. K. Nørskov and F. Studt, Monocopper active site for partial methane oxidation in Cu-exchanged 8MR zeolites, ACS Catal., 2016, 6, 6531-6536.

30 D. K. Pappas, et al., The nuclearity of the active site for methane to methanol conversion in Cu-mordenite: a quantitative assessment, J. Am. Chem. Soc., 2018, 140, 15270-15278.

31 V. L. Sushkevich, D. Palagin, M. Ranocchiari and J. A. van Bokhoven, Selective anaerobic oxidation of methane enables direct synthesis of methanol, Science, 2017, 356, 523-527.

32 G. Li, P. Vassilev, M. Sanchez-Sanchez, J. A. Lercher, E. J. Hensen and E. A. Pidko, Stability and reactivity of copper oxo-clusters in ZSM-5 zeolite for selective methane oxidation to methanol, J. Catal., 2016, 338, 305-312.

33 Z. Lan and S. M. Sharada, Computational strategies to probe $\mathrm{CH}$ activation in dioxo-dicopper complexes, Phys. Chem. Chem. Phys., 2018, 20, 25602-25614.

34 B. R. Goodman, W. F. Schneider, K. C. Hass and J. B. Adams, Theoretical analysis of oxygen-bridged $\mathrm{Cu}$ pairs in $\mathrm{Cu}$ exchanged zeolites, Catal. Lett., 1998, 56, 183-188.

35 B. L. Trout, A. K. Chakraborty and A. T. Bell, Local spin density functional theory study of copper ion-exchanged ZSM-5, J. Phys. Chem., 1996, 100, 4173-4179.

36 U. Deka, I. Lezcano-Gonzalez, B. M. Weckhuysen and A. M. Beale, Local environment and nature of $\mathrm{Cu}$ active sites in zeolite-based catalysts for the selective catalytic reduction of $\mathrm{NO}_{x}$, ACS Catal., 2013, 3, 413-427.

37 J. Dědeček, Z. Sobalík and B. Wichterlová, Siting and distribution of framework aluminium atoms in silicon-rich zeolites and impact on catalysis, Catal. Rev., 2012, 54, 135223.

38 C. Paolucci, A. A. Parekh, I. Khurana, J. R. Di Iorio, H. Li, J. D. Albarracin Caballero, A. J. Shih, T. Anggara, W. N. Delgass, J. T. Miller, F. H. Ribeiro, R. Gounder and W. F. Schneider, Catalysis in a cage: Condition-Dependent Speciation and Dynamics of Exchanged $\mathrm{Cu}$ Cations in SSZ13 Zeolites, J. Am. Chem. Soc., 2016, 138, 6028-6048.

39 J. R. Di Iorio and R. Gounder, Controlling the Isolation and Pairing of Aluminum in Chabazite Zeolites Using Mixtures of Organic and Inorganic Structure-Directing Agents, Chem. Mater., 2016, 28, 2236-2247.

40 J. R. Di Iorio, C. T. Nimlos and R. Gounder, Introducing catalytic diversity into single-site chabazite zeolites of fixed composition via synthetic control of active site proximity, ACS Catal., 2017, 7, 6663-6674.

41 E. Borfecchia, K. A. Lomachenko, F. Giordanino, H. Falsig, P. Beato, A. V. Soldatov, S. Bordiga and C. Lamberti, Revisiting the nature of $\mathrm{Cu}$ sites in the activated $\mathrm{Cu}-\mathrm{SSZ}-13$ catalyst for SCR reaction, Chem. Sci., 2014, 8, 548-563.

42 J. D. Albarracin-Caballero, I. Khurana, J. R. Di Iorio, A. J. Shih, J. E. Schmidt, M. Dusselier, M. E. Davis, A. Yezerets, J. T. Miller, F. H. Ribeiro and R. Gounder, Structural and kinetic changes to small-pore Cu-zeolites after hydrothermal aging treatments and selective catalytic reduction of $\mathrm{NO}_{x}$ with ammonia, React. Chem. Eng., 2017, 2, 168-179.

43 J. E. Schmidt, R. Oord, W. Guo, J. D. Poplawsky and B. M. Weckhuysen, Nanoscale tomography reveals the deactivation of automotive copper-exchanged zeolite catalysts, Nat. Commun., 2017, 8, 1666.

44 F. Göltl, P. Sautet and I. Hermans, The impact of finite temperature on the coordination of $\mathrm{Cu}$ cations in the zeolite SSZ-13, Catal. Today, 2016, 267, 41-46.

45 P. Chen, A. Khetan, M. Jabłońska, J. Simböck, M. Muhler, R. Palkovits, H. Pitsch and U. Simon, Local dynamics of copper active sites in zeolite catalysts for selective catalytic reduction of $\mathrm{NO}_{x}$ with $\mathrm{NH}_{3}$, Appl. Catal., B, 2018, 237, 263272.

46 H. Li, C. Paolucci and W. F. Schneider, Zeolite Adsorption Free Energies from $A b$ Initio Potentials of Mean Force, $J$. Chem. Theory Comput., 2018, 14, 929-938.

47 L. Chen, H. Falsig, T. V. Janssens, J. Jansson, M. Skoglundh and $\mathrm{H}$. Grönbeck, Effect of Al-distribution on oxygen activation over Cu-CHA, Catal. Sci. Technol., 2018, 8, 21312136.

48 F. Giordanino, P. N. R. Vennestrøm, L. F. Lundegaard, F. N. Stappen, S. Mossin, P. Beato, S. Bordiga and C. Lamberti, Characterization of Cu-exchanged SSZ-13: a comparative FTIR, UV-Vis, and EPR study with Cu-ZSM-5 and $\mathrm{Cu}-\beta$ with similar $\mathrm{Si} / \mathrm{Al}$ and $\mathrm{Cu} / \mathrm{Al}$ ratios, Dalton Trans., 2013, 42, 12741-12761.

49 A. Godiksen, F. N. Stappen, P. N. R. Vennestrøm, F. Giordanino, S. Birk Rasmussen, L. F. Lundegaard and S. Mossin, Coordination Environment of Copper Sites in $\mathrm{Cu}-\mathrm{CHA}$ Zeolite Investigated by Electron Paramagnetic Resonance, J. Phys. Chem. C, 2014, 118, 23126-23138.

50 R. Oord, J. E. Schmidt and B. M. Weckhuysen, Methane-tomethanol conversion over zeolite Cu-SSZ-13, and its comparison with the selective catalytic reduction of $\mathrm{NO}_{x}$ with $\mathrm{NH}_{3}$, Catal. Sci. Technol., 2018, 8, 1028-1038.

51 G. D. Lei, B. J. Adelman, J. Sárkány and W. M. H. Sachtler, Identification of copper(II) and copper(I) and their interconversion in Cu/ZSM-5 De-NO ${ }_{x}$ catalysts, Appl. Catal., $B, 1995$, 5, 245-256.

52 B. Modén, P. Da Costa, B. Fonfé, D. K. Lee and E. Iglesia, Kinetics and Mechanism of Steady-State Catalytic NO Decomposition Reactions on Cu-ZSM5, J. Catal., 2002, 209, 75-86.

53 B. Modén, P. Da Costa, D. K. Lee and E. Iglesia, Transient studies of oxygen removal pathways and catalytic redox cycles during NO decomposition on Cu-ZSM5, J. Phys. Chem. B, 2002, 106, 9633-9641.

54 P. J. Smeets, R. G. Hadt, J. S. Woertink, P. Vanelderen, R. A. Schoonheydt, B. F. Sels and E. I. Solomon, Oxygen precursor to the reactive intermediate in methanol synthesis by Cu-ZSM-5, J. Am. Chem. Soc., 2010, 132, 14736-14738.

55 J. S. Woertink, P. J. Smeets, M. H. Groothaert, M. A. Vance, B. F. Sels, R. A. Schoonheydt and E. I. Solomon, A $\left[\mathrm{Cu}_{2} \mathrm{O}\right]^{2+}$ Core in Cu-ZSM-5, the Active Site in the Oxidation of 
Methane to Methanol, Proc. Natl. Acad. Sci. U. S. A., 2009, 106, 18908-18913.

56 M. H. Groothaert, P. J. Smeets, B. F. Sels, P. A. Jacobs and R. A. Schoonheydt, Selective oxidation of methane by the bis( $\mu$-oxo)dicopper core stabilized on ZSM-5 and mordenite zeolites, J. Am. Chem. Soc., 2005, 127, 1394-1395.

57 S. Grundner, M. A. Markovits, G. Li, M. Tromp, E. A. Pidko, E. J. Hensen, A. Jentys, M. Sanchez-Sanchez and J. A. Lercher, Single-site trinuclear copper oxygen clusters in mordenite for selective conversion of methane to methanol, Nat. Commun., 2015, 6, 7546.

58 V. L. Sushkevich, D. Palagin and J. A. van Bokhoven, Effect of Active Sites Structure on Activity of Copper Mordenite in Aerobic and Anaerobic Conversion of Methane to Methanol, Angew. Chem., Int. Ed., 2018, 57, 8906-8910.

59 J. A. van Bokhoven and C. Lamberti, in XAFS Techniques for Catalysts, Nanomaterials, and Surfaces, ed. Y. Iwasawa, K. Asakura and M. Tada, Springer International Publishing, Cham, 2017; pp. 299-316.

60 N. Kosinov, C. Liu, E. J. Hensen and E. A. Pidko, Engineering of transition metal catalysts confined in zeolites, Chem. Mater., 2018, 30, 3177-3198.

61 D. Palagin, A. J. Knorpp, A. B. Pinar, M. Ranocchiari and J. A. van Bokhoven, Assessing the relative stability of copper oxide clusters as active sites of a CuMOR zeolite for methane to methanol conversion: size matters?, Nanoscale, 2017, 9, 1144-1153.

62 E. Borfecchia, D. K. Pappas, M. Dyballa, K. A. Lomachenko, C. Negri, M. Signorile and G. Berlier, Evolution of active sites during selective oxidation of methane to methanol over $\mathrm{Cu}-$ CHA and $\mathrm{Cu}-\mathrm{MOR}$ zeolites as monitored by operando XAS, Catal. Today, 2018, DOI: 10.1016/j.cattod.2018.07.028.

63 M. J. Henson, M. a. Vance, C. X. Zhang, H.-C. Liang, K. D. Karlin and E. I. Solomon, Resonance Raman investigation of equatorial ligand donor effects on the $\mathrm{Cu}_{2} \mathrm{O}_{2}{ }^{2+}$ core in end-on and side-on $\mu$-peroxo-dicopper(II) and bis- $\mu$-oxo-dicopper(III) complexes, J. Am. Chem. Soc., 2003, 125, 5186-5192.

64 P. Vanelderen, R. G. Hadt, P. J. Smeets, E. I. Solomon, R. A. Schoonheydt and B. F. Sels, Cu-ZSM-5: A biomimetic inorganic model for methane oxidation, J. Catal., 2011, 284, 157-164.

65 C. Paolucci, I. Khurana, A. A. Parekh, S. Li, A. J. Shih, H. Li, J. R. D. Iorio, J. D. Albarracin-caballero, A. Yezerets, J. T. Miller, W. N. Delgass, F. H. Ribeiro, W. F. Schneider and R. Gounder, Dynamic multinuclear sites formed by mobilized copper ions in $\mathrm{NO}_{x}$ selective catalytic reduction, Science, 2017, 357, 898-903.

66 J. S. McEwen, T. Anggara, W. F. Schneider, V. F. Kispersky, J. T. Miller, W. N. Delgass and F. H. Ribeiro, Integrated operando X-ray absorption and DFT characterization of $\mathrm{Cu}$ SSZ-13 exchange sites during the selective catalytic reduction of $\mathrm{NO}_{x}$ with $\mathrm{NH}_{3}$, Catal. Today, 2012, 184, 129-144.

67 P. J. Smeets, J. S. Woertink, B. F. Sels, E. I. Solomon and R. A. Schoonheydt, Transition-metal ions in zeolites: Coordination and activation of oxygen, Inorg. Chem., 2010, 49, 3573-3583.
68 A. Godiksen, P. N. R. Vennestrøm, S. B. Rasmussen and S. Mossin, Identification and quantification of copper sites in zeolites by electron paramagnetic resonance spectroscopy, Top. Catal., 2017, 60, 13-29.

69 B. E. R. Snyder, M. L. Bols, R. A. Schoonheydt, B. F. Sels and E. I. Solomon, Iron and Copper Active Sites in Zeolites and Their Correlation to Metalloenzymes, Chem. Rev., 2018, 118, 2718-2768.

70 S. Sklenak, P. C. Andrikopoulos, S. R. Whittleton, H. Jirglova, P. Sazama, L. Benco, T. Bucko, J. Hafner and Z. Sobalik, Effect of the $\mathrm{Al}$ siting on the structure of $\mathrm{Co}(\mathrm{II})$ and $\mathrm{Cu}(\mathrm{II})$ cationic sites in ferrierite. A periodic DFT molecular dynamics and FTIR study, J. Phys. Chem. C, 2013, 117, 3958-3968.

71 J. Luo, D. Wang, A. Kumar, J. Li, K. Kamasamudram, N. Currier and A. Yezerets, Identification of two types of $\mathrm{Cu}$ sites in $\mathrm{Cu} / \mathrm{SSZ}-13$ and their unique responses to hydrothermal aging and sulfur poisoning, Catal. Today, 2016, 267, 3-9.

72 F. Goeltl, P. Muller, P. Uchupalanun, P. Sautet and I. Hermans, Developing a Descriptor-Based Approach for CO and NO Adsorption Strength to Transition Metal Sites in Zeolites, Chem. Mater., 2017, 29, 6434-6444.

73 D. Harris and M. Bertolucci, Symmetry and Spectroscopy: An Introduction to Vibrational and Electronic Spectroscopy, Dover Books on Chemistry Series, Dover Publications, 1989.

74 E. I. Solomon, D. E. Heppner, E. M. Johnston, J. W. Ginsbach, J. Cirera, M. Qayyum, M. T. KieberEmmons, C. H. Kjaergaard, R. G. Hadt and L. Tian, Copper active sites in biology, Chem. Rev., 2014, 114, 3659-3853.

75 B. R. Goodman, K. C. Hass, W. F. Schneider and J. B. Adams, Cluster Model Studies of Oxygen-Bridged $\mathrm{Cu}$ Pairs in $\mathrm{Cu}-$ ZSM-5 Catalysts, J. Phys. Chem. B, 1999, 103, 10452-10460.

76 M. H. Mahyuddin, T. Tanaka, Y. Shiota, A. Staykov and K. Yoshizawa, Methane Partial Oxidation over $\left[\mathrm{Cu}_{2}(\mu-\mathrm{O})\right]^{2+}$ and $\left[\mathrm{Cu}_{3}(\mu-\mathrm{O})\right]^{2+}$ Active Species in Large-Pore Zeolites, ACS Catal., 2018, 8, 1500-1509.

77 B. C. Knott, C. T. Nimlos, D. J. Robichaud, M. R. Nimlos, S. Kim and R. Gounder, Consideration of the Aluminum Distribution in Zeolites in Theoretical and Experimental Catalysis Research, ACS Catal., 2018, 8, 770-784.

78 I. Lezcano-Gonzalez, U. Deka, B. Arstad, A. Van Yperen-De Deyne, K. Hemelsoet, M. Waroquier, V. Van Speybroeck, B. M. Weckhuysen and A. M. Beale, Determining the storage, availability and reactivity of $\mathrm{NH}_{3}$ within $\mathrm{Cu}-$ Chabazite-based Ammonia Selective Catalytic Reduction systems, Phys. Chem. Chem. Phys., 2014, 16, 1639-1650.

79 F. Giordanino, E. Borfecchia, K. A. Lomachenko, A. Lazzarini, G. Agostini, E. Gallo, A. V. Soldatov, P. Beato, S. Bordiga and C. Lamberti, Interaction of $\mathrm{NH}_{3}$ with CuSSZ-13 catalyst: A complementary FTIR, XANES, and XES study, J. Phys. Chem. Lett., 2014, 5, 1552-1559.

80 S. Li, H. Li, R. Gounder, A. Debellis, I. B. Müller, S. Prasad, A. Moini and W. F. Schneider, First-Principles Comparison of Proton and Divalent Copper Cation Exchange Energy Landscapes in SSZ-13 Zeolite, J. Phys. Chem. C, 2018, 122, 23564-23573. 
81 A. Martini, E. Borfecchia, K. A. Lomachenko, I. Pankin, C. Negri, G. Berlier, P. Beato, H. Falsig, S. Bordiga, C. Lamberti and I. A. Pankin, Composition-driven $\mathrm{Cu}-$ speciation and reducibility in $\mathrm{Cu}-\mathrm{CHA}$ zeolite catalysts: a multivariate XAS/FTIR approach to complexity, Chem. Sci., 2017, 8, 6836-6851.

82 C. W. Andersen, E. Borfecchia, M. Bremholm, M. R. V. Jørgensen, P. N. R. Vennestrøm, C. Lamberti, L. F. Lundegaard and B. B. Iversen, Redox-Driven Migration of Copper Ions in the Cu-CHA Zeolite as Shown by the In Situ PXRD/XANES Technique, Angew. Chem., Int. Ed., 2017, 56, 10367-10372.

83 G. Berlier, V. Crocellà, M. Signorile, E. Borfecchia, F. Bonino and S. Bordiga, in Struct. Bond., ed. M. P. F.Mingos, Springer, Berlin, Heidelberg, 2018, ch. 1, pp. 1-64.

84 A. Martini, E. Alladio and E. Borfecchia, Determining $\mathrm{Cu}-$ Speciation in the Cu-CHA Zeolite Catalyst: The Potential of
Multivariate Curve Resolution Analysis of In Situ XAS Data, Top. Catal., 2018, 61, 1396-1407.

85 A. Godiksen, O. L. Isaksen, S. B. Rasmussen, P. N. Vennestrøm and S. Mossin, Site-Specific Reactivity of Copper Chabazite Zeolites with Nitric Oxide, Ammonia, and Oxygen, ChemCatChem, 2018, 10, 366-370.

86 C. W. Andersen, M. Bremholm, P. N. R. Vennestrom, A. B. Blichfeld, L. F. Lundegaard and B. B. Iversen, Location of $\mathrm{Cu}^{2+}$ in CHA zeolite investigated by X-ray diffraction using the Rietveld/maximum entropy method, IUCrJ, 2014, 1, 382-386.

87 R. Oord, Spectroscopic Insights into Copper-Based Microporous Zeolites for $\mathrm{NH}_{3}$-SCR of $\mathrm{NO}_{x}$ and Methane-toMethanol Activation, Ph.D. thesis, Utrecht University, 2017. 88 F. Gao, N. M. Washton, Y. Wang, M. Kollár, J. Szanyi and C. H. Peden, Effects of Si/Al ratio on Cu/SSZ-13 NH 3-SCR catalysts: Implications for the active $\mathrm{Cu}$ species and the roles of Brønsted acidity, J. Catal., 2015, 331, 25-38. 